\title{
Caregiver maltreatment causes altered neuronal DNA methylation in female rodents
}

\author{
JENNIFER BLAZE AND TANIA L. ROTH \\ University of Delaware
}

\begin{abstract}
Negative experiences with a caregiver during infancy can result in long-term changes in brain function and behavior, but underlying mechanisms are not well understood. It is our central hypothesis that brain and behavior changes are conferred by early childhood adversity through epigenetic changes involving DNA methylation. Using a rodent model of early-life caregiver maltreatment (involving exposure to an adverse caregiving environment for postnatal days 1-7), we have previously demonstrated abnormal methylation of DNA associated with the brain-derived neurotrophic factor (Bdnf) gene in the medial prefrontal cortex (mPFC) of adult rats. The aim of the current study was to characterize Bdnf DNA methylation in specific cell populations within the mPFC. In the prefrontal cortex, there is approximately twice as many neurons as glia, and studies have recently shown differential and distinctive DNA methylation patterns in neurons versus nonneurons. Here, we extracted nuclei from the mPFC of adult animals that had experienced maltreatment and used fluorescenceactivated cell sorting to isolate cell types before performing bisulfite sequencing to estimate methylation of cytosine-guanine sites. Our data indicate that earlylife stress induced methylation of DNA associated with $B d n f I V$ in a cell-type and sex-specific manner. Specifically, females that experienced early-life maltreatment exhibited greater neuronal cytosine-guanine methylation compared to controls, while no changes were detected in $B d n f$ methylation in males regardless of cell type. These changes localize the specificity of our previous findings to mPFC neurons and highlight the capacity of maltreatment to cause methylation changes that are likely to have functional consequences for neuronal function.
\end{abstract}

Experiencing stress during sensitive periods of development, especially infancy, is a predisposing factor for various types of psychopathology, including depression, anxiety, schizophrenia, and posttraumatic stress disorder (Cicchetti \& Toth, 2005; Teicher et al., 2003). Although some individuals cope successfully and function competently despite significant early-life adversity (Cicchetti \& Rogosch, 2009), it is more common to see deleterious consequences. The behavioral sequelae of childhood maltreatment include the development of disorganized attachment, trouble with affect regulation, problems with peer relationships, and the presence of numerous psychiatric disorders (Cicchetti \& Toth, 1995; Cirulli et al., 2009; Gershon, Sudheimer, Tirouvanziam, Williams, \& O'Hara, 2013; Lupien, McEwen, Gunnar, \& Heim, 2009; Meaney, 2001). In addition, children who are maltreated exhibit a host of biological consequences over

This research was supported by NIGMS (1P20GM103653) and a University of Delaware Graduate Fellowship. We thank Dr. Robert Akins (Nemours-Alfred I. DuPont Hospital for Children), Dr. Jaclyn Schwarz (University of Delaware), Dr. Lynn Opdenaker (Center for Translational Cancer Research and Christiana Care Hospital), and Dr. Danay Baker-Andresen (University of Queensland) for their help with troubleshooting the fluorescence-activated cell sorting technique. We thank the Delaware Biotechnology Institute for the use of their core facilities (supported by the Delaware INBRE program, with Grant P20 GM103446 from NIGMS and the state of Delaware). We also thank Angela Maggio and Kristyn Borrelli for their assistance with behavioral coding.

Address correspondence and reprint requests to: Tania L. Roth, Department of Psychological and Brain Sciences, University of Delaware, 108 Wolf Hall, Newark, DE 19716; E-mail: troth@ psych.udel.edu. time, including altered hypothalamus-pituitary-adrenal axis function (Gunnar, Frenn, Wewerka, \& Van Ryzin, 2009; Heim et al., 2000, 2002; Loman \& Gunnar, 2010), abnormal volume of specific brain regions (Cohen et al., 2006; Vythilingam et al., 2002), and atypical expression of genes and proteins important in development, plasticity, stress regulation, and inflammation (Carpenter et al., 2010; Kim-Cohen et al., 2006; McGowan et al., 2009; Mehta et al., 2013).

Preclinical studies using animal models parallel many of the findings in the human literature (for reviews see Blaze \& Roth, 2015; Heim \& Nemeroff, 2001; Lutz \& Turecki, 2014). To model early-life adversity, rodent models have capitalized on low levels of maternal care (Caldji, Diorio, \& Meaney, 2000; Caldji et al., 1998; Francis, Diorio, Liu, \& Meaney, 1999; Liu et al., 1997; Weaver et al., 2004), maternal separation (Boku et al., 2015; Braun, Lange, Metzger, \& Poeggel, 1999; Chocyk et al., 2013; Franklin et al., 2010; Kundakovic, Lim, Gudsnuk, \& Champagne, 2013; Monroy, HernándezTorres, \& Flores, 2010; Muhammad, Carroll, \& Kolb, 2012; Uchida et al., 2010; Wang et al., 2014; Weiss, Franklin, Vizi, \& Menaey, 2011; Zhang, Qin, \& Zhao, 2013), or experimentally manipulated exposure to painful stimuli or caregiver maltreatment (Blaze, Scheuing, \& Roth, 2013; Chen et al., 2010; Ivy, Brunson, Sandman, \& Baram, 2008; Ivy et al., 2010; Moriceau, Shinoya, Jakubs, \& Sullivan, 2009; Roth, Lubin, Funk, \& Sweatt, 2009; Roth \& Sullivan, 2005). All of these models have shown behavioral and neurobiological alterations reminiscent of those in humans. 
One way that stress may lead to neurobiological and behavioral deficits is through epigenetic modifications such as DNA methylation. DNA methylation is a chemical modification to chromatin in which a methyl group is added to DNA, a reaction that normally suppresses gene transcription. Evidence has also shown DNA methylation to have activational effects on gene transcription, although less is known about this phenomenon (Chahrour et al., 2008). Data continue to accumulate showing that early-life maltreatment produces changes in DNA methylation in the brain and periphery of both humans and animals (for recent reviews, see (Blaze \& Roth, 2015; Lutz \& Turecki, 2014). Our lab has provided substantial evidence of altered brain-derived neurotrophic factor (Bdnf) methylation in the rat brain following exposure to caregiver maltreatment (Blaze, Asok, \& Roth, 2015; Blaze \& Roth, 2013; Blaze et al., 2013; Roth et al., 2009; Roth, Matt, Chen, \& Blaze, 2014). The Bdnf gene codes for a protein (BDNF) that is crucial for neurodevelopment and implicated in learning and memory processes as well as many psychiatric disorders (Martinowich, Manji, \& Lu, 2007; Monteggia et al., 2007). Changes in Bdnf methylation following early-life stress in our rodent model include an increase in methylation in the whole prefrontal cortex (PFC; Roth et al., 2009) as well as within the medial PFC (mPFC; Blaze et al., 2013, 2015).

Multiple studies have emerged in recent years suggesting that DNA methylation patterns differ between neurons and nonneurons for multiple gene loci in the human (Guintivano, Aryee, \& Kaminsky, 2013; Iwamoto et al., 2011; Kozlenkov et al., 2014; Lister et al., 2013; Nishioka et al., 2013) and rodent (Li, Baker-Andresen, Zhao, Marshall, \& Bredy, 2014; Lister et al., 2013; Nishioka et al., 2013) PFC. For example, $\mathrm{Li}$ et al. (2014) recently showed that rodent ventromedial PFC neurons display greater global DNA methylation compared to nonneurons. Our previous work utilized a homogenate of brain tissue for downstream methylation analysis, thus providing an estimate of methylation across the heterogeneous cell populations within the tissue. Because at least one-third of cells in the PFC are glia (including astrocytes, oligodendrocytes, and microglia; Azevedo et al., 2009; Guintivano et al., 2013), and because all central nervous system cell types express Bdnf at some level (Aid, Kazantseva, Piirsoo, Palm, \& Timmusk, 2007; Nakajima \& Kohsaka, 2001; Riley, Cope, \& Buck, 2004; Wei, Lin, \& Tu, 2010), it poses the question of in which cell type are our maltreatment-induced $B d n f$ methylation changes occurring.

To build upon our previous research, the current study aimed to determine if maltreatment-induced Bdnf DNA methylation patterns differ for neurons and nonneurons. Previously, we found sex- and treatment-specific changes in the adult (postnatal day 90 [PN90]) mPFC in a heterogeneous population of cells (Blaze et al., 2013, 2015). In the current study, we used fluorescence-activated cell sorting to isolate neurons and nonneurons (glia) from the mPFC of adult (PN90) male and female rats that experienced early-life caregiver maltreatment or nurturing care and measured DNA methylation of $B d n f I V$.

\section{Methods}

\section{Animals}

For this study, subjects were 62 adult (PN90) male and female outbred Long-Evans rats that experienced our caregiver manipulations during infancy (9-11/sex/condition). These animals were obtained from our in-house breeding colony and maintained in a temperature-controlled (range $=20 \pm 1{ }^{\circ} \mathrm{C}$ ) and light-controlled colony room (12-hr light/12-hr dark cycle with lights on at 6:00 a.m.) with ad libitum access to food and water. For breeding in our colony, one male and one female rat (obtained from Harlan) were placed together in a wirebottomed cage and separated once a sperm plug was detected (indicating successful copulation). Pregnant females were housed alone in standard cages with plentiful wood shavings and ad libitum access to food and water. The day of birth was indicated as PNO and pups were culled to 5-6 males and 5-6 females before caregiving manipulations took place on PN1-7. No first-time mothers were used as experimental or stimulus caregivers. All procedures were approved by the University of Delaware Animal Care and Use Committee.

\section{Early-life caregiving paradigm}

We performed caregiving manipulations using a well-established protocol previously reported in our laboratory (Asok, Bernard, Rosen, Dozier, \& Roth, 2014; Blaze et al., 2013, 2015; Blaze \& Roth, 2013; Roth et al., 2009, 2014) and adapted from others (Ivy et al., 2008; Roth \& Sullivan, 2005). On PN1, each experimental litter was separated into three groups of 2 male and 2 female pups and marked numerically with nontoxic permanent marker for identification. During experimental manipulations, which were conducted at different, unpredictable times every day from PN1 to 7, pups in the maltreatment and cross-foster care conditions were transported to a room and placed with another lactating dam for $30 \mathrm{~min}$ (matched for postpartum age and diet to the biological mom). The maltreatment group experienced a dam that had been placed in the chamber with no time to habituate and minimal nesting resources (i.e., wood chip bedding). The cross-foster care group experienced a dam (also matched for postpartum age and diet to the biological mom) that had been given $1 \mathrm{hr}$ to habituate in her chamber and was provided with ample nesting resources to care for the pups. The normal care condition was left with the biological mother in the home cage during the 30-min sessions. After exposures, pups were returned to the biological mother until the following day's session. After PN7, litters were left undisturbed until weaning at PN21-23 and then housed with a same-sex, same-condition littermate until PN90.

Caregiving behaviors directed toward pups were scored by trained observers via live observation and/or video recordings. Behavioral data were collected by tallying nurturing and aversive caregiving behaviors in 5-min time-bins during the 30-min sessions. Scores were then averaged across all 
seven exposure days. Ultrasonic and audible vocalizations from pups were also scored, and these measures were collected with a bat detector (40 kHz; Batbox III, NHBS Ltd., UK) and audible voice recorder during each session. Vocalizations were coded by trained observers who tallied the presence of an ultrasonic or audible vocalization in each minute of the 30-min session, and these data were likewise averaged across the seven exposure sessions.

\section{Tissue collection}

Brains were collected at PN90 via rapid decapitation at baseline conditions (i.e., with minimal disturbance/stimulation to animals when removing them from their home cage) following light isoflurane anesthesia. After removal, brains were immediately sliced into 1 -mm coronal sections using a brain matrix and flash frozen with 2-methylbutane on untreated slides. Slides were frozen at $-80{ }^{\circ} \mathrm{C}$ until later processing. In addition, postmortem vaginal lavages were performed to determine estrous cycle stage for all females.

\section{Fluorescence-activated cell sorting (FACS)}

To isolate neurons and nonneurons, we used a technique created by the Akbarian lab (Matevossian \& Akbarian, 2008) and adapted for rodents by the Bredy lab (Li et al., 2014; depicted in Figure 1). The MPFC was dissected on dry ice and placed immediately in nuclear extraction buffer $(0.32 \mathrm{M}$ sucrose, $10 \mathrm{~m} M$ Tris $\mathrm{HCl}, 5 \mathrm{~m} M \mathrm{CaCl}_{2}, 3 \mathrm{~m} M \mathrm{Mg}\left(\mathrm{C}_{2} \mathrm{H}_{3} \mathrm{O}_{2}\right)_{2}$, $0.1 \mathrm{~m} M$ EDTA, $1 \mathrm{~m} M$ dithiothreitol, $0.1 \%$ Triton-X-100, and Halt Protease Inhibitor Cocktail), homogenized, and filtered through a $40-\mu \mathrm{m}$ cell strainer. After centrifugation, nuclei were resuspended and incubated for $1 \mathrm{hr}$ with staining mixtures. To isolate neurons with immunostaining, we used an antibody specific to NeuN (1:1200, Millipore) along with the secondary antibody Alexafluor 488 (1:700, Life Technologies Corp.). We also stained with DAPI to identify nuclei versus debris. After staining, samples were transported on ice to the Helen F. Graham Cancer Center at Christiana Hospital, where they were sorted into two populations (DAPI+l $\mathrm{NeuN}+$ and DAPI+/NeuN-) with the FACSAria II Flow Cytometer. For each sample, we also had an unstained control that was run prior to the DAPI/NeuN stained sample to control for background. Cells were sorted in $1 \mathrm{X}$ PBS, stored on ice for 30-60 min during transport back to the lab, and DNA was extracted immediately using the Quick-gDNA MicroPrep kit (Zymo) according to the manufacturer's protocol. Concentration and purity of DNA was determined using a Nanodrop spectrophotometer.

\section{DNA methylation assays}

After FACS, we used direct bisulfite sequencing polymerase chain reactions (BSP) to measure $B d n f I V$ methylation in mPFC tissue of adult rats that experienced our caregiver manipulations. This gene has been well characterized in rodent

\section{Fluorescence-activated cell sorting (FACS)}

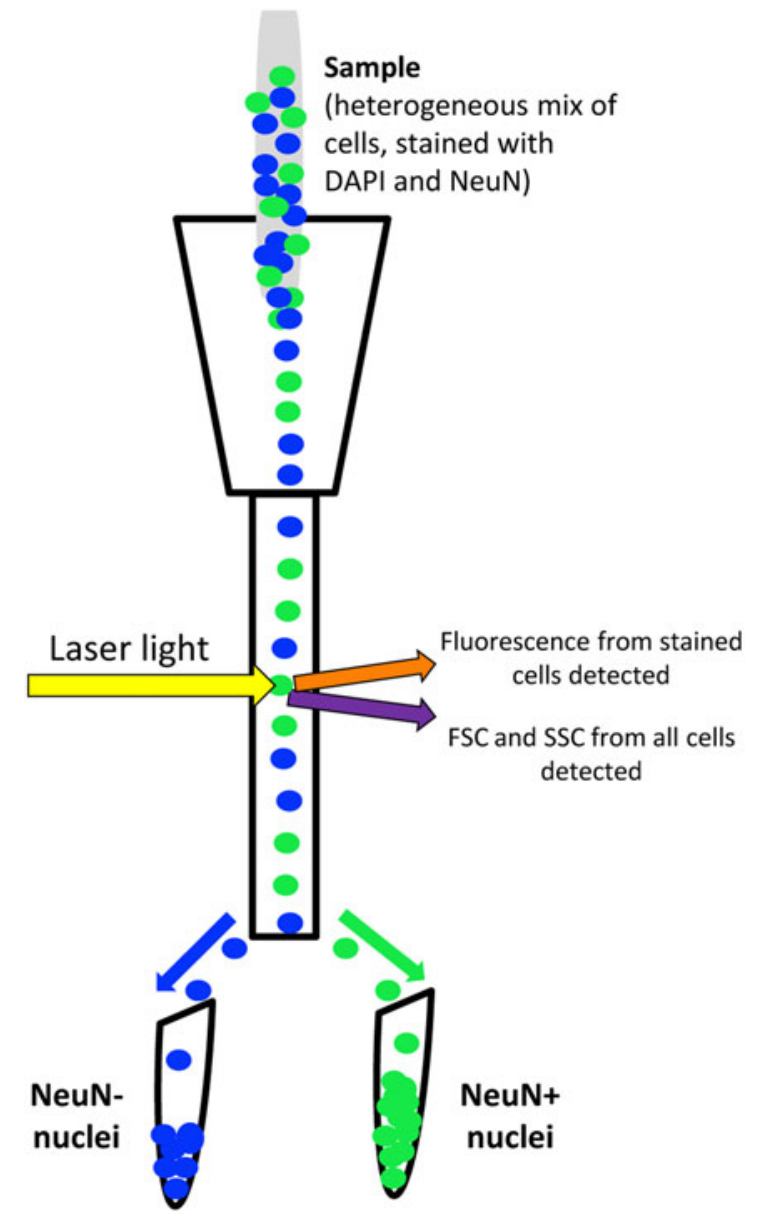

Figure 1. (Color online) Schematic of fluorescence-activated cell sorting. Fluorescence-activated cell sorting is a more advanced form of flow cytometry. With this technique, heterogeneous mixtures of cells in a sample are passed through a nozzle in "single file" fashion. A laser shines on the cells, scattering light in various directions in order to detect size (forward scatter) and granularity (side scatter) of cells. Cells that are stained with a fluorescent antibody are also detected, and electromagnets separate the populations of cells into different tubes by assigning a positive or negative charge to the stained or unstained cells. DAPI, nuclear stain; NeuN, neuronal stain; FSC, forward scatter (cell size); SSC, side scatter (cell complexity/granularity).

and human studies and consists of nine noncoding exons that each splice to the common coding exon IX (Aid et al., 2007). BSP is a technique used previously in our lab (Roth et al., 2009, 2014) to estimate methylation at individual cytosine sites of DNA associated with Bdnf IV. Following established protocols (Parrish, Day, \& Lubin, 2012; Roth et al., 2009, 2014; Roth, Zoladz, Sweatt, \& Diamond, 2011), BSP was performed on PN90 bisulfite-treated DNA (Epitect Bisulfite Kit, Qiagen) using primers specific to $B d n f I V$ (for primer sequences, see Lubin, Roth, \& Sweatt, 2008; Roth et al., 2009), and samples were sent to the University of Delaware Sequencing and Genotyping Center for direct bisulfite sequencing using the reverse primer. Methylation for each 
sample was measured using Chromas software. We confirmed the accuracy of this technique by assessing methylated standards (Rat Pre-mixed Calibration Standards, Epigendx) ranging from $0 \%$ to $100 \%$ methylation and performing a linear regression on methylation values, $F(1,38)=214.3$, $p<.001, R^{2}=.8494$.

\section{Statistical analyses}

Caregiver behaviors and pup vocalizations were analyzed with one- and two-way analyses of variance (ANOVAs) with post hoc tests when appropriate (unpaired $t$ tests or multiple $t$ tests with Bonferonni correction). For both neurons and nonneurons, BSP data were analyzed with two-way ANOVAs comparing average methylation (across all 12 sites) between treatment group and sex $(3 \times 2)$, with post hoc tests when necessary (e.g., multiple $t$ tests with Bonferroni correction). In addition, twoway ANOVAs (with multiple $t$ tests with Bonferonni correction) were performed on each of the 12 cytosine-guanine (CG) sites for males and females in both the neuronal and nonneuronal populations. Postmortem vaginal lavages were performed to determine estrous cycle stage for all females. We determined estrus cycle stage by assessing the presence and proportions of leukocytes, nucleated epithelial cells, and/ or cornified cells (Bianchi \& Tanno, 2001; Caligioni, 2009). Due to low sample numbers in certain stages of cycling, we combined metestrus/diestrus and proestrus/estrus for analyses, as done by others (Trainor et al., 2011). Two-way ANOVAs for average methylation and at each individual CG site revealed no significant effect of estrous cycle stage, pup treatment, or an interaction (all $p \mathrm{~s}>.05$ ). Moreover, average methylation levels were consistent across all estrous cycle stages (all $p \mathrm{~s}>.05$ ).

\section{Results}

\section{Caregiving behavior and pup vocalizations}

We observed caregiver behaviors and pup vocalizations during our 30-min sessions on PN1-7 to confirm that maltreated pups were experiencing an adverse caregiving environment. We used a two-way ANOVA to analyze pup condition (normal care, cross-foster care, or maltreatment) and overall caregiver behavior (aversive or nurturing) and found a significant effect of caregiver behavior, $F(2,36)=67.73, p<.001$, and a Pup Condition $\times$ Caregiver Behavior interaction, $F(2,36)=$ $30.08, p<.001$. Specifically, dams in the maltreatment condition showed significantly more aversive behaviors and less nurturing behaviors toward pups in comparison to dams in the normal care and cross-foster care conditions (Figure 2). Their aversive behaviors included frequent stepping on, dragging, dropping, active avoidance, and roughly handling of pups (Figure 3).

We also measured audible and ultrasonic vocalizations from pups during our manipulations and averaged values across all seven days. There was a significant effect of pup condition on both audible, $F(2,18)=5.019, p<.05$, and

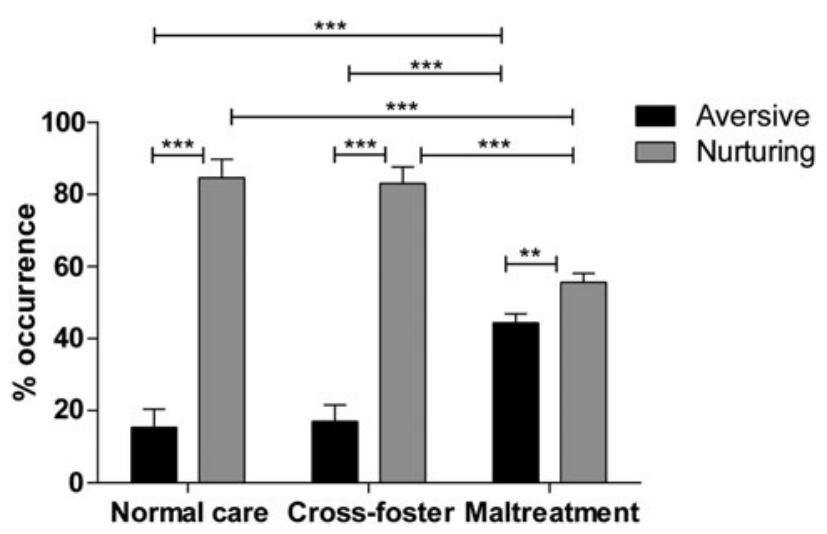

Figure 2. Overall caregiving behavior across the seven sessions. Pups in the maltreatment condition experienced significantly more aversive caregiving behaviors compared to pups in the normal care and cross-foster care conditions. Further, pups in the maltreatment condition experienced less nurturing behaviors compared to the other groups. ${ }^{*} p<.01$, *** $p<.001$; error bars represent standard error of the mean; $n=7$ dams per condition.

ultrasonic, $F(2,18)=6.132, p<.01$, vocalizations during exposure sessions (Figure 4). Specifically, maltreated pups emitted more audible vocalizations than pups in the cross-foster, marginal effect: $t(18)=2.419, p=.079$, and normal care, $t(18)=2.981, p<.05$, conditions (Figure 4a). The maltreatment group also emitted significantly more ultrasonic vocalizations compared to the cross-foster, $t(18)=2.742$, $p<.05$, and normal care, $t(18)=3.258, p<.05$, conditions (Figure 4b). Together, behavioral results indicate that pups in our maltreatment condition experienced an adverse caregiving environment while pups in our control conditions (cross-foster care and normal care) experienced a nurturing caregiving environment. These observations are consistent with those in our prior reports (Blaze et al., 2013, 2015; Blaze \& Roth, 2013; Roth et al., 2009, 2014).

\section{FACS analysis}

We used FACS to identify and separate neurons and nonneurons in $\mathrm{mPFC}$ brain samples from rats that had undergone our caregiver manipulations. Figure 5 depicts a representative set of scatterplots from a sorted sample. Unstained control samples were run for each sample and yielded minimal to no background. The gate for DAPI+ events, or nuclei, was used as the parent population for further delineation into the $\mathrm{NeuN}+$ and NeuN- populations. The population of NeuN + (neuronal) nuclei and the population of NeuN- (nonneuronal) nuclei were separated in order to avoid cross-contamination of opposing cell type in our sorted populations of nuclei (5.7\% of DAPI+ nuclei). The NeuN+ (neuronal) population of nuclei was significantly larger than the NeuN- (nonneuronal) population of nuclei, with an average of $61 \% \mathrm{NeuN}+$ nuclei and $\sim 32 \%$ NeuN- nuclei, $t(110)=18.84, p<.001$ (Figure 6), which is in line with previous reports of cell composition in the mPFC (Li et al., 2014; Willing, Kim, Brodsky, Cortes, \& Juraska, 2014). 


\section{Aversive caregiving behaviors}

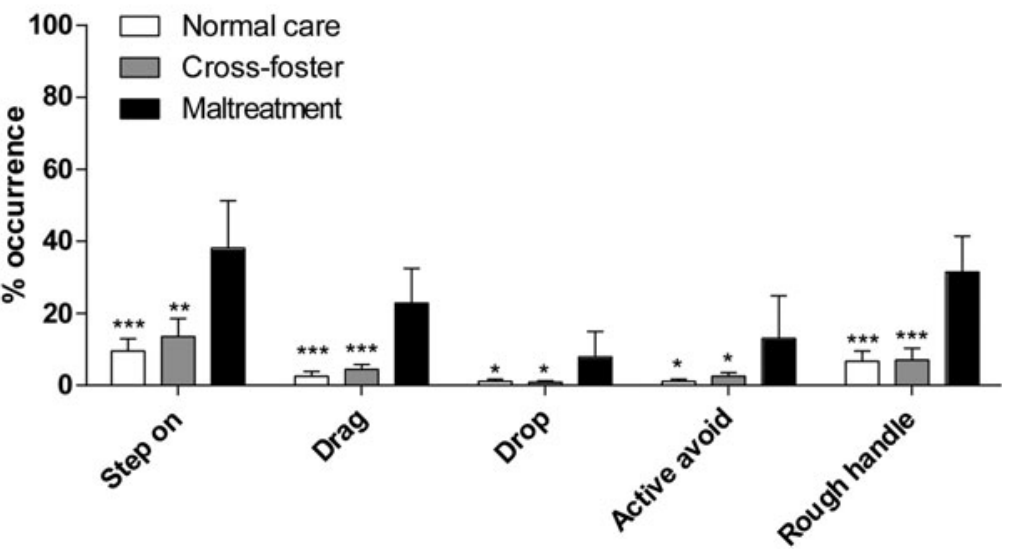

Figure 3. Individual aversive caregiving behaviors displayed across the seven sessions. Dams in the maltreatment condition displayed significantly more aversive caregiving behaviors, including stepping on, $F(2,18)=11.88 p<.001$, dragging, $F(2,18)=22.50 p<.001$, dropping, $F(2,18)=6.09 p<.01$, actively avoiding, $F(2,18)=5.89 p<.05$, and roughly handling pups, $F(2,18)=17.97 p<.001 . * p<.05$, $* * p<.01, * * * p<.001$ versus maltreatment; normal versus cross-foster comparisons not significant; error bars represent standard error of the mean; $n=7$ dams per condition.

\section{Neuronal DNA methylation}

We used BSP to measure DNA methylation of $B d n f I V$ in the neuronal and nonneuronal cell populations produced after

\section{Pup vocalizations}
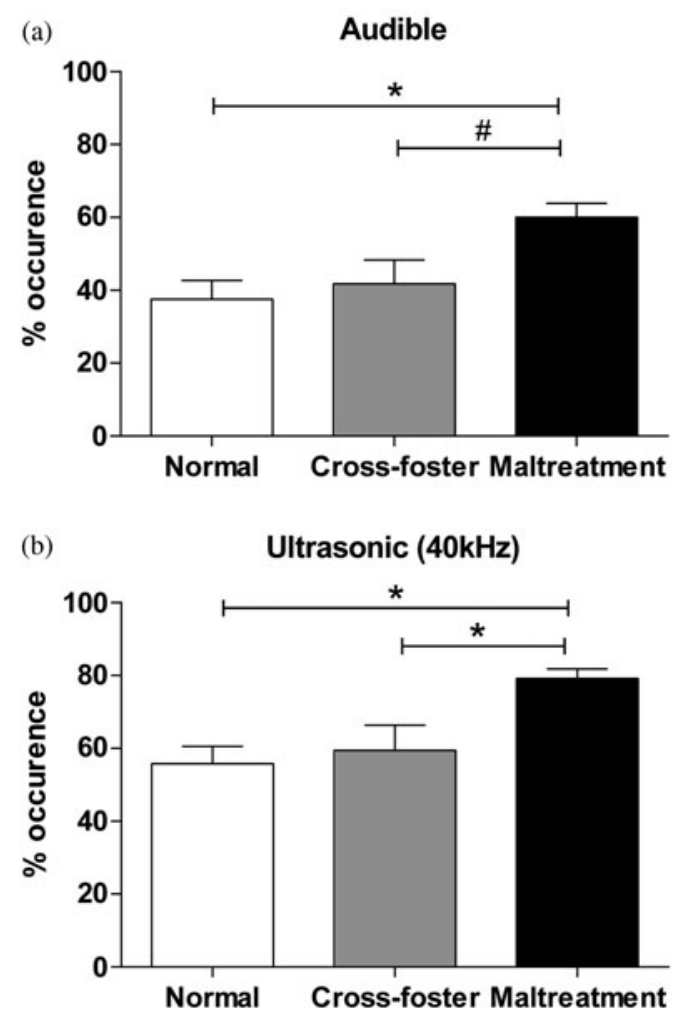

Figure 4. Pup vocalizations during caregiver manipulations. Maltreated pups emitted more audible and ultrasonic vocalizations than pups in the normal care and cross-foster conditions. ${ }^{*} p<.05, \# p=.079$; error bars represent standard error of the mean; $n=7$ litters.
FACS. A two-way ANOVA, 2 (sex) $\times 3$ (pup treatment), of average methylation percentages (across all CG sites) revealed no effect of sex, $F(2,55)=0.3841, p=.54$, or treatment, $F(2,55)=1.553, p=.22$, alone, but there was a significant interaction of early-life caregiving experience and sex, $F(2,55)=7.235, p<.01$ (Figure 7). Bonferonni-corrected $t$ tests showed more methylation in maltreated females in comparison to normal care females, $t(55)=3.539, p<$ .05 , cross-foster care females, $t(55)=3.035, p=.055$, and maltreated males, $t(55)=3.431, p<.05$.

To identify any sex- or treatment-specific effects at individual CG sites, we ran two-way ANOVAs, 2 (sex) $\times 3$ (treatment), for each of the $12 \mathrm{CG}$ sites (Figure 8). There was an interaction of sex and pup treatment at CG site $3, F(2,55)$ $=3.654, p<.05$, site $4, F(2,55)=6.789, p<.01$, site 5 , $F(2,55)=3.857, p<.05$, site $6, F(2,55)=3.660, p<$ .05 , site $11, F(2,55)=5.924, p<.01$, and site $12, F(2$, $38)=3.499, p<.05$. Multiple $t$ tests with Bonferroni correction at these sites revealed no effect of treatment on males (Figure 8a; $p \mathrm{~s}>.05$ ), but maltreated females had greater methylation in comparison to normal controls at site $4, t$ $(55)=3.895, p<.01$, site $5, t(55)=3.076, p<.05$, and site $6, t(55)=3.149, p<.05$ (Figure $8 \mathrm{~b}$ ). Further, maltreated females had higher methylation levels at site 4 compared to cross-foster females, $t(55)=3.326, p<.05$, and at site 4 , $t(55)=3.228, p<.05$, and site $6, t(55)=3.304, p<$ .05 , and site $11, t(55)=3.243, p<.05$, compared to maltreated males.

\section{Nonneuronal DNA methylation}

We likewise used BSP to measure methylation of nonneurons in the $\mathrm{mPFC}$ of rats that experienced our caregiving manipulations in infancy. Average methylation (across all 12 sites) did not differ between sexes, $F(2,46)=0.6649, p=.42$, pup 


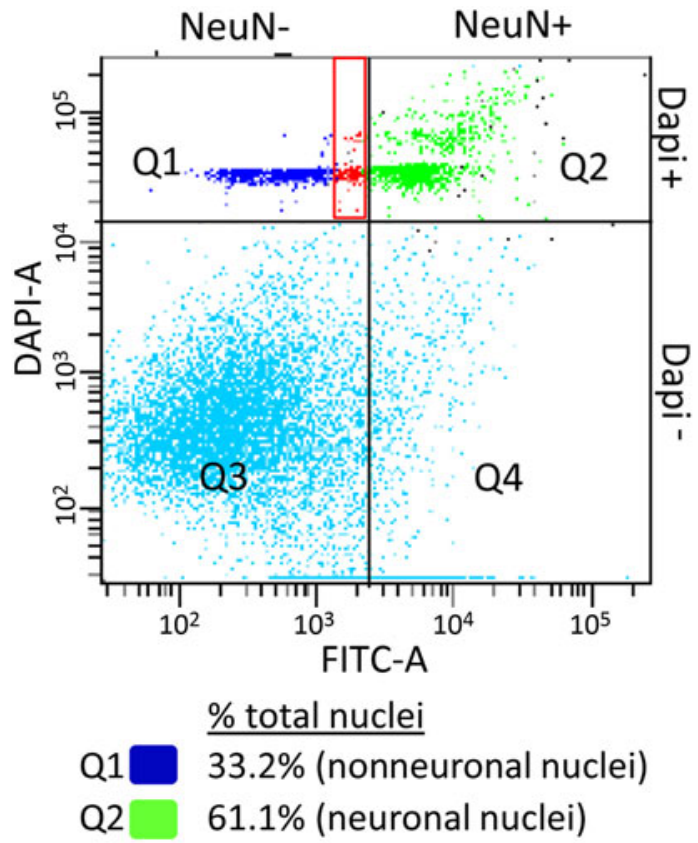

Figure 5. (Color online) Fluorescence-activated cell sorting analysis of normal adult rat medial prefrontal cortex using NeuN staining to identify neuronal nuclei. Representative scatterplot depicts cells/nuclei stained with DAPI and nuclei stained with NeuN (a neuronal specific nuclear protein) and a fluorescent secondary antibody. Q1 and Q2 together represent all DAPI+ nuclei (blue, green, red online only), Q2 (green online only) represents DAPI+/NeuN+ nuclei (neurons), and Q1 (dark blue online only) represents DAPI $+/ \mathrm{NeuN}$ - nuclei (nonneurons). Percentages represent the proportion of DAPI+ nuclei that were sorted into both $\mathrm{NeuN}+$ and NeuN- populations. The remaining nuclei (5.7\%; red box online only) located in the middle of Q1 and Q2 were avoided to eliminate cross-contamination of the two populations when sorting. DAPI, nuclear stain; FITC, fluorescence associated with NeuN and secondary antibody.

treatment group, $F(2,46)=0.2798, p=.76$, nor was methylation affected by an interaction between sex and pup treatment group, $F(2,46)=0.6384, p=.64$ (Figure 9). Further, methylation at individual CG sites was not affected by sex, pup treatment, or their interaction (all $p \mathrm{~s}>.05$; Figure 10).

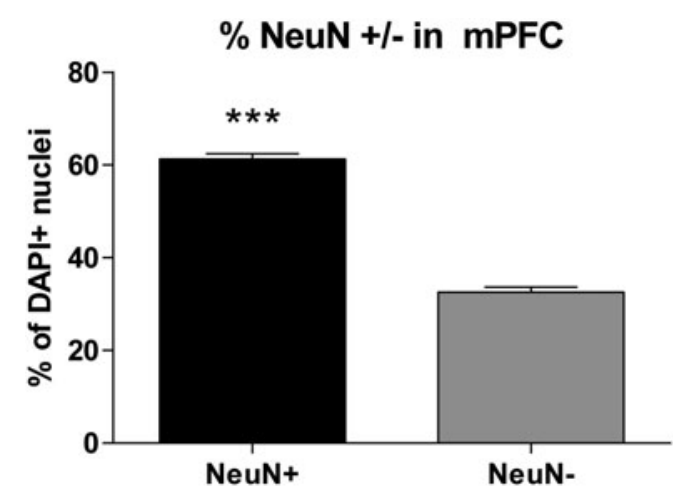

Figure 6. Percentage of NeuN $+/-$ nuclei in the medial prefrontal cortex. After averaging all fluorescence-activated cell sorting analyses from medial prefrontal cortex samples, we confirmed that staining with $\mathrm{NeuN}+$ yielded $\sim 60 \%$ neuronal nuclei and $\sim 33 \% \mathrm{NeuN}-$ nuclei. $* * * p<.001$; error bars represent standard error of the mean, $n=56 /$ group.

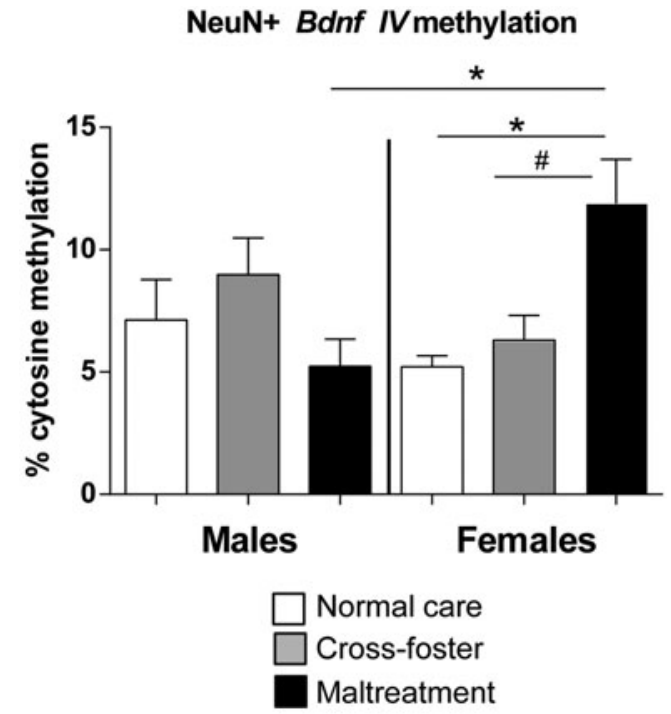

Figure 7. Average NeuN $+B d n f I V$ methylation across all cytosine-guanine sites. After averaging methylation percentages across all 12 cytosine-guanine sites, maltreated females had increased neuronal Bdnf IV methylation compared to normal care control and cross-foster care females and maltreated males. There were no effects of early-life caregiving experience on neuronal $B d n f I V$ methylation in males. ${ }^{*} p<.05$, $\# p=.055$; error bars represents standard error of the mean; $n=9-11 /$ group.

\section{Discussion}

In the current study, we aimed to characterize methylation of DNA associated with $B d n f I V$ in $\mathrm{mPFC}$ neurons and nonneurons from adult rats with a history of maltreatment. We previously showed that in adult females, maltreatment during infancy yields greater $B d n f I V$ methylation in the mPFC (Blaze et al., 2013, 2015). In these prior studies, data were generated from a heterogeneous mix of cells from mPFC tissue, not controlling for cell type. Recent work has shown evidence of cell-type specific DNA methylation patterns in neurons versus glia (Li et al., 2014; Lister et al., 2013), and altered $B d n f$ methylation of these cell types may have different downstream consequences for brain function and behavior (Martinowich et al., 2007; Wei et al., 2010). To investigate the effects of maltreatment on methylation within specific cell types here, we used FACS to isolate neuronal and nonneuronal cell populations from $\mathrm{mPFC}$ tissue before measuring $B d n f$ IV DNA methylation.

First, FACS data revealed that about $60 \%$ of nuclei in our mPFC samples were neurons, while the rest were glia. Other groups have published similar data consistent with our neuron:glia ratio for the $\mathrm{mPFC}$ ( $\mathrm{Li}$ et al., 2014; Willing et al., 2014). Second, FACS data revealed that maltreated females had higher levels of neuronal methylation in comparison to female controls and maltreated males. Site-specific neuronal methylation for maltreated females was also highest at CG sites 4, 5, and 6. Moreover, we showed that Bdnf IV methylation was unrelated to stage of estrous cycle in these animals, which was unknown in our previous study (Blaze et al., 2013). Third, when we examined methylation in 


\section{NeuN+ Bdnf IV methylation}

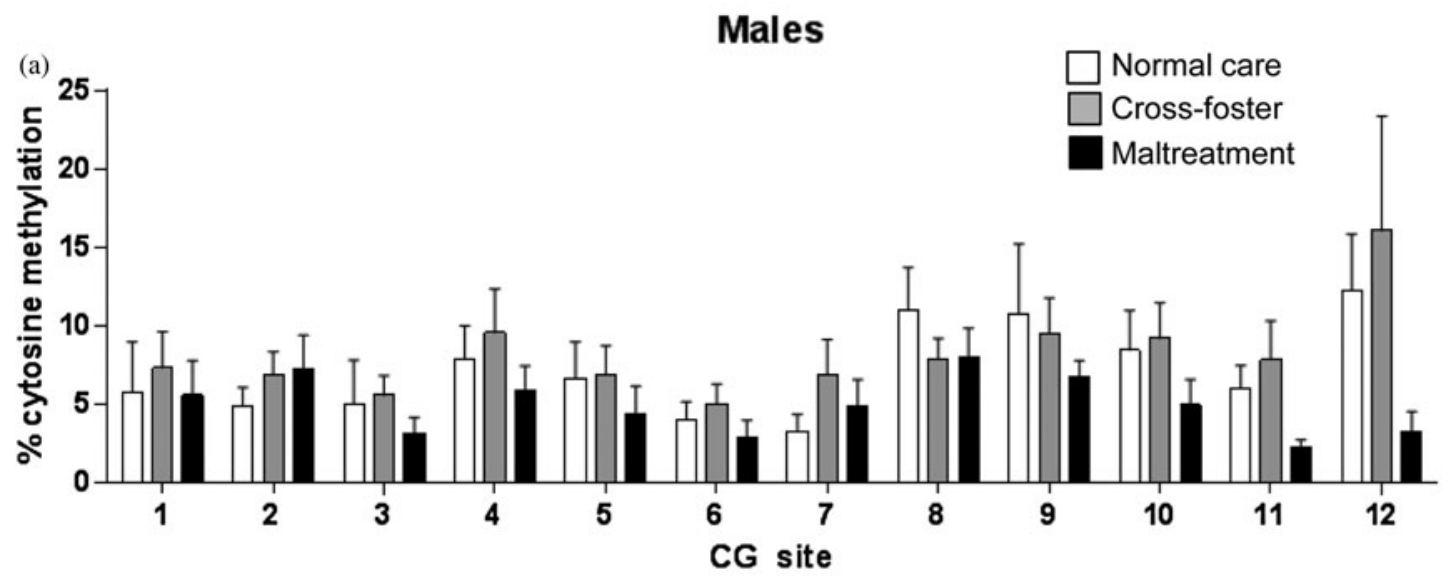

(b)

Females

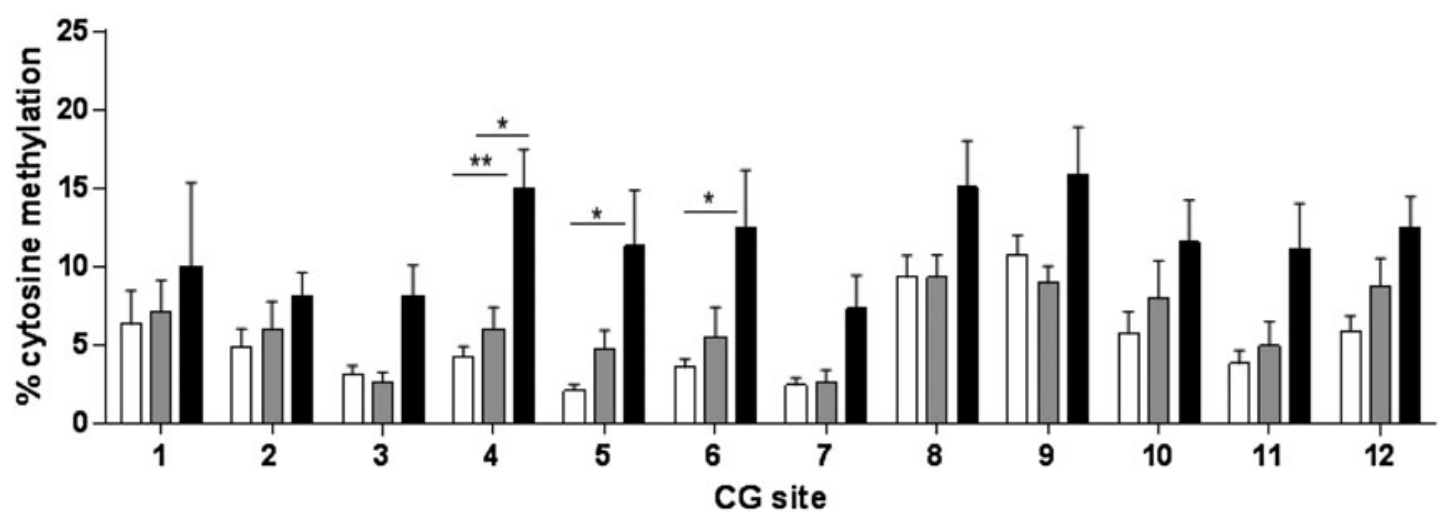

Figure 8. NeuN $+B d n f I V$ site-specific methylation. While there were no effects of treatment on male neuronal $B d n f I V$ methylation at individual cytosine-guanine sites, maltreated females had significant methylation at cytosine-guanine sites 4-6 compared to female controls. ${ }^{*} p<.05$, $*^{*} p<.01$; error bars represent standard error of the mean; $n=9-11$ group.

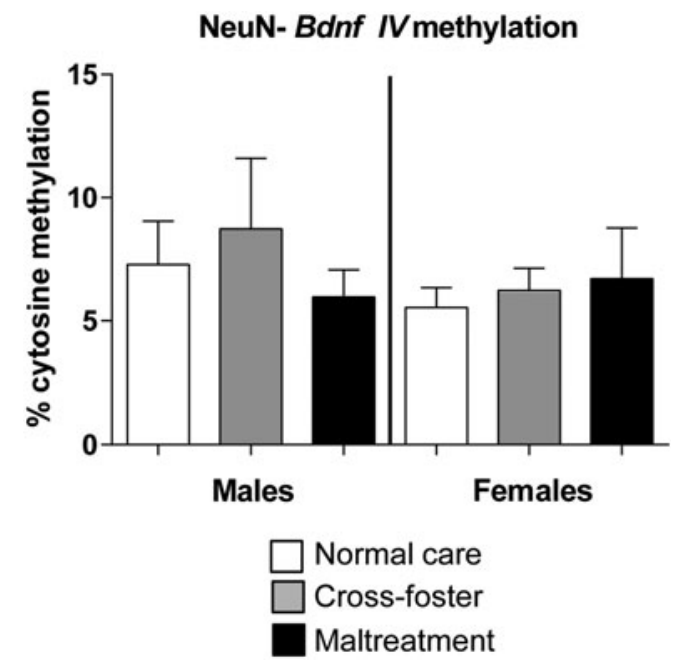

Figure 9. Average NeuN- Bdnf IV methylation across all cytosine-guanine sites. There was no effect of early-life caregiving condition or sex on average nonneuronal $B d n f I V$ methylation in the medial prefrontal cortex. Error bars represent standard error of the mean; $n=8-10 /$ group. nonneurons after FACS, we found no changes in average or site-specific $B d n f I V$ methylation in our maltreated male or maltreated female rats. In all, our $B d n f$ neuronal methylation patterns paralleled those previously observed for bulk mPFC tissue (Blaze et al., 2013, 2015). Due to the prevalence of Bdnf in neurons compared to glia (Kawamoto, Nakamura, Kawamata, Akiguci, \& Kimura, 1999; Martinowich et al., 2003), it appears that maltreatment-induced changes are taking place where most $B d n f$ is located.

Sex differences in behavioral, cellular, and molecular responses to early-life experiences have consistently been reported (for reviews, see Bale \& Epperson, 2015; Bock, Rether, Groeger, Xie, \& Braun, 2014; McEwen, 2010; Teicher et al., 2003). Here we found greater Bdnf IV DNA methylation in the mPFC of female rats. This is an observation we have reported in other studies (Blaze et al., 2013, 2015) and is consistent with other sex-specific epigenetic effects that continue to emerge in the study of early adversity (e.g., Cicchetti, Rogosch, Hecht, Cick, \& Hetzel, 2014; Essex et al., 2013; Franklin et al., 2010; Kundakovic et al., 2013; 


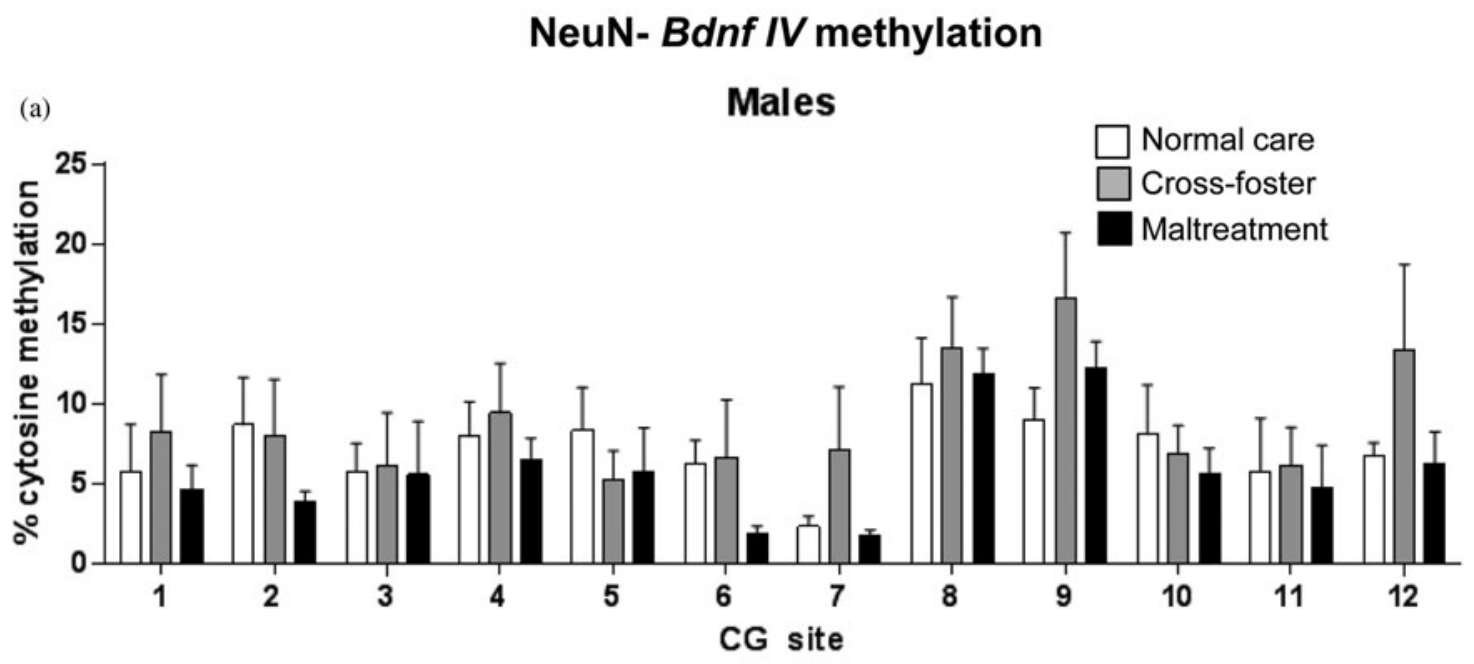

(b)

Females

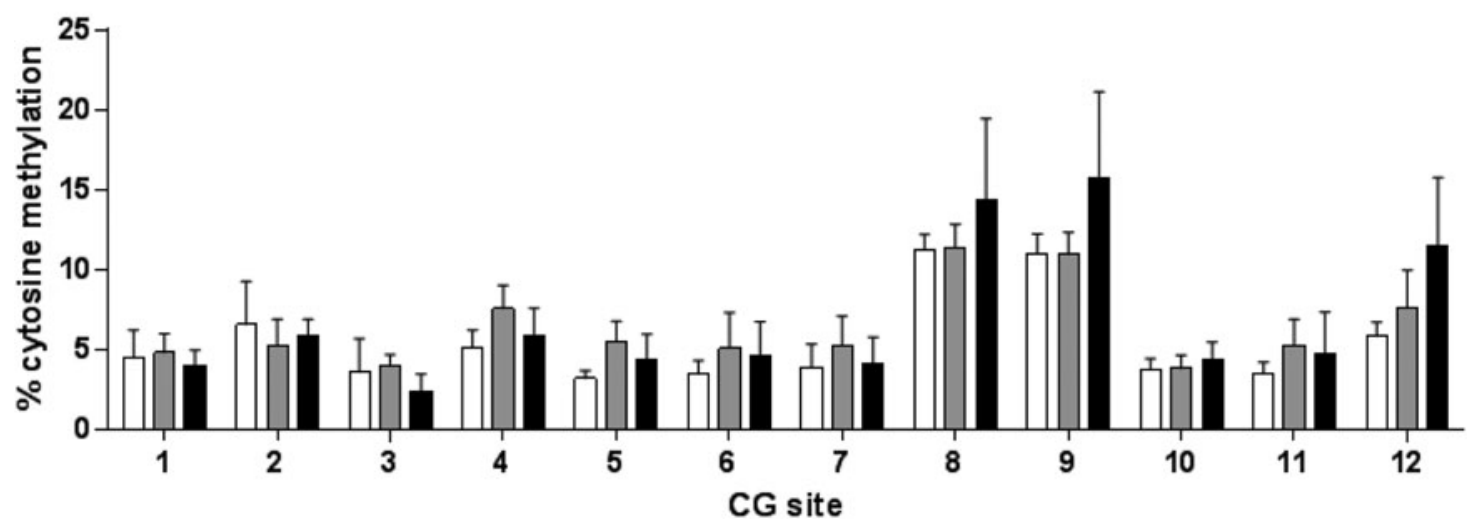

Figure 10. NeuN- Bdnf IV site-specific methylation. There was no effect of sex or early-life caregiving condition on nonneuronal $B d n f I V$ methylation in the male or female medial prefrontal cortex at any individual cytosine-guanine sites. Error bars represent standard error of the mean; $n=8-10 /$ group.

Melas et al., 2013; Mueller \& Bale, 2008; St.-Cyr \& McGowan, 2015). As DNA methylation is sexually dimorphic in the developing brain (Kigar, Chang, Hayne, Kala, \& Auger, 2016; Kolodkin \& Auger, 2011; McCarthy et al., 2009; Nugent \& McCarthy, 2011; Nugent et al., 2015; Spiers et al., 2015), this likely plays some role in the differential sensitivity to and/or outcomes associated with maltreatment we have observed in male and female rats here and in our other studies (Blaze et al., 2013, 2015; Blaze \& Roth, 2013; Roth et al., 2014). In addition, it is known that within the nest, dams spend less time nursing and licking female pups (Hao, Huang, Nielsen, \& Kosten, 2011; Moore \& Morelli, 1979). Due to limitations in our experimental setup, we were unable to identify caregiving behaviors directed toward individual pups, but it is certainly plausible that differential care toward males and females both within our experimental chambers or within the home cage is another contributing factor to the sex differences we observed. We acknowledge the long-term behavioral and health consequences of maltreatment in humans is not limited to females (e.g., Dube et al., 2005; Teicher \& Samson, 2016; Thompson, Kingree, \& Desai, 2004); thus, we predict that though we did not detect any changes in methylation at this one gene locus in maltreated males, they have other loci with aberrant methylation.

Many studies have demonstrated the deleterious effects of early-life stress on the structure and function of neurons. For example, rat pups that receive low levels of maternal care or maternal deprivation exhibit impairments in measures of dendritic complexity and synaptic plasticity in the adult hippocampus and PFC (Bagot et al., 2009; Chocyk et al., 2013; Monroy et al., 2010; Pascual \& Zamora-Leon, 2007). Further, maternally deprived rats show impairments in hippocampal neurogenesis in response to a later stress challenge (Mirescu, Peters, \& Gould, 2004). While neuronal-specific effects of early-life stress are abundant in the literature, only few changes to glia have been reported (Bolton et al., 2013; Leventopoulos et al., 2007). Glial-specific effects of early-life stress include altered production of pro-inflammatory cytokines from microglia following pre- and early-postnatal stress (Bolton et al., 2013) and a reduction in astrocyte density following maternal deprivation during infancy (Leventopoulos et al., 2007). 
In neurons, $B d n f$ is upregulated following neuronal activity (Lubin et al., 2008; Martinowich et al., 2003) and commonly related to synaptic plasticity, memory, and mood (Martinowich et al., 2007; Nakajima et al., 2001; Nakajima \& Kohsaka, 2001). Animals with decreased Bdnf levels show impairments in long-term potentiation and hippocampal-dependent memory (Monteggia et al., 2004) along with abnormal cortical dendrite structure (Gorski, Zailer, Tamowski, \& Jones, 2003) and impaired neurogenesis (Lee, Duan, \& Mattson, 2002). Altered Bdnf functioning is thus likely one of the mechanisms by which early-life stress could produce abnormalities in neural structure and function, and our data here highlight that DNA methylation could be involved in this process.

Neurons and glia are known to work in tandem to regulate brain function in response to environmental stimuli by secreting BDNF protein, providing support for cells of the brain in times of stress or environmental insult (Coull et al., 2005; Nakajima \& Kohsaka, 2001; Wu et al., 2008). Although glia and neurons express $B d n f$ and its receptor TrkB in the PFC, its neurotrophic effects can differ across cell types and time points. For example, $B d n f$ mRNA and protein in astrocytes and microglia are quickly upregulated in response to physical injury (Wei et al., 2010) or an immune challenge (Nakajima et al., 2001), playing roles in neuroprotection. Neuronal levels of $B d n f$ mRNA following stress are sensitive to time course, such that an acute, short stressor (i.e., $60 \mathrm{~min}$ immobilization) increases $B d n f$ mRNA, but repeated stress decreases Bdnf mRNA (Alleva \& Santucci, 2001; Bilbo et al., 2008; Marmigère, Givalois, Rage, Arancibia, \& Tapia-Arancibia, 2003; Rasmusson, Shi, \& Duman, 2002). Here we only measured DNA methylation at one time point (adulthood, about 3 months past our experimental manipulations); thus, it is possible that $B d n f$ methylation patterns in neurons and glia would be different at a time point closer to the insult and earlier in development.

Clinical studies have recently begun to delve into the translational aspects of DNA methylation induced by early-life stress (Keller, Sarchiapone, \& Zarrilli, 2010; McGowan et al., 2009; Naumova et al., 2012; Oberlander et al., 2008; Perroud et al., 2011; Tyrka, Price, Marsit, Walters, \& Carpenter, 2012; Unternaehrer et al., 2015). For Bdnf, it has been shown that borderline personality disorder patients that experienced childhood trauma have higher levels of methylation in peripheral blood leukocytes (Perroud et al., 2013; Prados et al., 2015). Another study found that adults who experienced childhood maltreatment also showed increased methylation of $B d n f$ DNA in whole blood (Unternaehrer et al., 2015). These findings are consistent with our observations of maltreatmentinduced increases in central nervous system $B d n f$ methylation (Blaze et al., 2013, 2015; Roth et al., 2009). Further, increased $B d n f$ methylation has also been associated with depression (Fuchikami et al., 2011; Song et al., 2014) and schizophrenia (Ikegame et al., 2013).

Nevertheless, there is increasing evidence that normalizing $B d n f$ methylation patterns may be a mechanism by which phar- macological or psychological therapy exert their beneficial effects on patients (Chen, Ernst, \& Turecki, 2011; Perroud et al., 2013). For example, postmortem PFC samples (Chen et al., 2011) and blood (Lopez et al., 2013) from depressed patients displayed higher $B d n f I V$ mRNA levels after treatment with antidepressants, which corresponded to a decrease in histone methylation at H3K27 (a repressive epigenetic marker). In addition, bipolar patients undergoing dialectical behavioral therapy displayed decreased $B d n f$ methylation over time if they were responding to treatment (Perroud et al., 2013). The concordance between brain and blood or saliva methylation patterns is still largely unknown, but recent studies have shown correlations between blood or saliva and brain methylation for certain genes (Ewald et al., 2014; Walton et al., 2016), including DNA associated with $B d n f$ (Smith et al., 2015; Stenz et al., 2015). While the search for biomarkers that can be used in the clinic is ongoing, epigenetic studies continue to highlight the utility of $B d n f$ methylation as a strong candidate.

We acknowledge several limitations of the current study. Technical limitations of tissue processing for FACS prevented us from retrieving RNA, so we were unable to measure gene expression for these animals. We also sorted populations of cells based on the presence of $\mathrm{NeuN}$, and all NeuN- nuclei were a mixture of glia, containing oligodendrocytes, microglia, and astrocytes. We were thus unable to further separate this population to identify if $B d n f$ methylation was altered in certain glial subtypes, and some studies have shown distinct methylation patterns within glial subtypes for certain gene loci (Perisic et al., 2010; Schwarz, Hutchinson, \& Bilbo, 2011). Finally, a limitation of the current bisulfite conversion technique used here is the lack of differentiation between 5-methylcytosine and 5-hydroxymethylcytosine. Because these two marks may have different effects on transcription and behavior (Sun, Zang, Shu, \& Li, 2014), it would be useful in the future to use another technique, such as oxidative bisulfite sequencing, to distinguish 5-methylcytosine from 5hydroxymethylcytosine (Booth et al., 2013).

Additional work is certainly necessary to causally link these maltreatment-induced changes (and of course other epigenetic changes that are presumably occurring) with behavior. Relevant to this Special Issue is the question of how these changes might relate to attachment. Infant attachment security is heavily influenced by environmental factors (e.g., Bokhorst et al., 2003; Dozier, Stoval, Albus, \& Bates, 2001; Roisman \& Fraley, 2008); thus, critical variables like parental stimulation and sensitivity (or the lack thereof) could become embedded in DNA methylation levels, including that of $B d n f$, which in turn influences gene activity, neural development, synapse maturation, and circuitry function supporting caregiver-infant attachment. It is plausible that sustained changes would also contribute to disorganized and insecure attachments often seen in adults with a history of maltreatment (Riggs, Cusimano, \& Benson, 2011; Shah, Fonagy, \& Strathearn, 2010; Styron \& Janoff-Bulman, 1997).

Further, changes in DNA methylation may be a mechanism by which caregiver-based interventions exert their 
beneficial effects on attachment organization. While clinical studies have demonstrated the deleterious effects of insecure and disorganized infant-caregiver attachment, including altered hypothalamus-pituitary-adrenal axis, brain development, and behavioral and emotional responses to stress (Bernard et al., 2012; Berthelot et al., 2015; Fisher, Gunnar, Dozier, Bruce, \& Pears, 2006; Lowell, Renk, \& Adgate, 2014; Lyons-Ruth, Prchtel, Yoon, Anderson, \& Teicher, 2016; Pickreign Stronach et al., 2011), caregiver-based interventions can alter attachment organization and change these outcomes (Bernard et al., 2012; Cicchetti, Rogosch, \& Toth, 2006; Fisher et al., 2006). It is likely that methylation of DNA associated with the $B d n f$ gene and many others are responsive to these interventions, and altering methylation

\section{References}

Aid, T., Kazantseva, A., Piirsoo, M., Palm, K., \& Timmusk, T. (2007). Mouse and rat bdnf gene structure and expression revisited. Journal of Neuroscience Research, 85, 525-535.

Alleva, E., \& Santucci, D. (2001). Psychosocial vs. "physical" stress situations in rodents and humans: Role of neurotrophins. Physiology \& Behavior, 73, 313-320.

Asok, A., Bernard, K., Rosen, J. B., Dozier, M., \& Roth, T. L. (2014). Infantcaregiver experiences alter telomere length in the brain. PLOS ONE, 9, e101437.

Azevedo, F. A., Carvalho, L. R., Grinberg, L. T., Farfel, J. M., Ferretti, R. E., Leite, R. E., . . . Herculano-Houzel, S. (2009). Equal numbers of neuronal and nonneuronal cells make the human brain an isometrically scaled-up primate brain. Journal of Comparative Neurology, 513, 532-541.

Bagot, R. C., van Hasselt, F. N., Champagne, D. L., Meaney, M. J., Krugers, H. J., \& Joëls, M. (2009). Maternal care determines rapid effects of stress mediators on synaptic plasticity in adult rat hippocampal dentate gyrus. Neurobiology of Learning and Memory, 92, 292-300.

Bale, T. L., \& Epperson, C. N. (2015). Sex differences and stress across the lifespan. Nature Neuroscience, 18, 1413-1420.

Bernard, K., Dozier, M., Bick, J., Lewis-Morrarty, E., Lindhiem, O., \& Carlson, E. (2012). Enhancing attachment organization among maltreated children: Results of a randomized clinical trial. Child Development, 83, 623-636.

Berthelot, N., Ensink, K., Bernazzani, O., Normandin, L., Luyten, P., \& Fonagy, P. (2015). Intergenerational transmission of attachment in abused and neglected mothers: The role of trauma-specific reflective functioning. Infant Mental Health Journal, 36, 200-212.

Bianchi, F. J., \& Tanno, A. P. (2001). Determination of the estrous cycle phase of rats: Some helpful considerations. Brazilian Journal of Biology, 62, 609-614.

Bilbo, S. D., Barrientos, R. M., Eads, A. S., Northcutt, A., Watkins, L. R., Rudy, J. W., \& Maier, S. F. (2008). Early-life infection leads to altered bdnf and IL-1 $\beta$ mRNA expression in rat hippocampus following learning in adulthood. Brain, Behavior, and Immunity, 22, 451-455.

Blaze, J., Asok, A., \& Roth, T. L. (2015). Long-term effects of early-life caregiving experiences on brain-derived neurotrophic factor histone acetylation in the adult rat mPFC. Stress, 18, 607-615.

Blaze, J., \& Roth, T. L. (2013). Exposure to caregiver maltreatment alters expression levels of epigenetic regulators in the medial prefrontal cortex. International Journal of Developmental Neuroscience, 31, 804-810.

Blaze, J., \& Roth, T. L. (2015). Evidence from clinical and animal model studies of the long-term and transgenerational impact of stress on DNA methylation. Seminars in Cell \& Developmental Biology, 43, 76-84.

Blaze, J., Scheuing, L., \& Roth, T. L. (2013). Differential methylation of genes in the medial prefrontal cortex of developing and adult rats following exposure to maltreatment or nurturing care during infancy. Developmental Neuroscience, 35, 306-316.

Bock, J., Rether, K., Groeger, N., Xie, L., \& Braun, K. (2014). Perinatal programming of emotional brain circuits: An integrative view from systems to molecules. Frontiers in Neuroscience, $8,11$.

Bokhorst, C. L., Bakermans-Kranenburg, M. J., Pasco Fearon, R. M., van IJzendoorn, M. H., Fonagy, P., \& Schuengel, C. (2003). The importance could drive changes in gene activity and neural circuitry necessary to promote a behavioral change. Studies that examine methylation pre- and postintervention are critical to elucidate the role of methylation/demethylation in conferring phenotypic change, including attachment.

In summary, our data here of the neuronal-specific nature of $B d n f$ methylation changes contribute to a growing understanding of the capacity of maltreatment to have long-term consequences at the molecular and cellular levels. As we continue to unravel the link between DNA methylation and phenotype, understanding the complexity and specificity of epigenetic changes brought about by early-life caregiving is an important step toward understanding the link between early-life stress and psychopathology.

of shared environment in mother-infant attachment security: A behavioral genetic study. Child Development, 74, 1769-1782.

Boku, S., Toda, H., Nakagawa, S., Kato, A., Inoue, T., Koyama, T., . . Kusumi, I. (2015). Neonatal maternal separation alters the capacity of adult neural precursor cells to differentiate into neurons via methylation of retinoic acid receptor gene promoter. Biological Psychiatry, 77, 335-344.

Bolton, J. L., Huff, N. C., Smith, S. H., Mason, S. N., Foster, W. M., Auten, R. L., \& Bilbo, S. D. (2013). Maternal stress and effects of prenatal air pollution on offspring mental health outcomes in mice. Environmental Health Perspectives, 12, 1075-1082.

Booth, M. J., Ost, T. W., Beraldi, D., Bell, N. M., Branco, M. R., Reik, W., \& Balasubramanian, S. (2013). Oxidative bisulfite sequencing of 5methylcytosine and 5-hydroxymethylcytosine. Nature Protocols, 8, 1841-1851.

Braun, K., Lange, E., Metzger, M., \& Poeggel, G. (1999). Maternal separation followed by early social deprivation affects the development of monoaminergic fiber systems in the medial prefrontal cortex of Octodon degus. Neuroscience, 95, 309-318.

Caldji, C., Diorio, J., \& Meaney, M. J. (2000). Variations in maternal care in infancy regulate the development of stress reactivity. Biological Psychiatry, 48, 1164-1174.

Caldji, C., Tannenbaum, B., Sharma, S., Francis, D., Plotsky, P. M., \& Meaney, M. J. (1998). Maternal care during infancy regulates the development of neural systems mediating the expression of fearfulness in the rat. Proceedings of the National Academy of Sciences, 95, 5335-5340.

Caligioni, C. (2009). Assessing reproductive status/stages in mice. Current Protocols in Neuroscience, Appendix 4. doi:10.1002/0471142301.nsa04is48

Carpenter, L. L., Gawuga, C. E., Tyrka, A. R., Lee, J. K., Anderson, G. M., \& Price, L. H. (2010). Association between plasma IL-6 response to acute stress and early-life adversity in healthy adults. Neuropsychopharmacology, 35, 2617-2623.

Chahrour, M., Jung, S. Y., Shaw, C., Zhou, X., Wong, S. T., Qin, J., \& Zoghbi, H. Y. (2008). Mecp2, a key contributor to neurological disease, activates and represses transcription. Science, 320, 1224-1229.

Chen, E. S., Ernst, C., \& Turecki, G. (2011). The epigenetic effects of antidepressant treatment on human prefrontal cortex BDNF expression. International Journal of Neuropsychopharmacology, 14, 427-429.

Chen, Y., Rex, C. S., Rice, C. J., Dubé, C. M., Gall, C. M., Lynch, G., \& Baram, T. Z. (2010). Correlated memory defects and hippocampal dendritic spine loss after acute stress involve corticotropin-releasing hormone signaling. Proceedings of the National Academy of Sciences, 107, 13123-13128.

Chocyk, A., Bobula, B., Dudys, D., Przyborowska, A., Majcher-Maślanka, I., Hess, G., \& Wędzony, K. (2013). Early-life stress affects the structural and functional plasticity of the medial prefrontal cortex in adolescent rats. European Journal of Neuroscience, 38, 2089-2107.

Cicchetti, D., \& Rogosch, F. A. (2009). Adaptive coping under conditions of extreme stress: Multilevel influences on the determinants of resilience in maltreated children. New Directions for Child and Adolescent Development, 2009, 47-59.

Cicchetti, D., Rogosch, F. A., Hecht, K. F., Crick, N. R., \& Hetzel, S. (2014) Moderation of maltreatment effects on childhood borderline personality 
symptoms by gender and oxytocin receptor and FK506 binding protein 5 genes. Development and Psychopathology, 26, 831-849.

Cicchetti, D., Rogosch, F., \& Toth, S. L. (2006). Fostering secure attachment in infants in maltreating families through preventive interventions. Development and Psychopathology, 18, 623-649.

Cicchetti, D., \& Toth, S. L. (1995). A developmental psychopathology perspective on child abuse and neglect. Journal of the American Academy of Child \& Adolescent Psychiatry, 34, 541-565.

Cicchetti, D., \& Toth, S. L. (2005). Child maltreatment. Annual Review of Clinical Psychology, 1, 409-438.

Cirulli, F., Francia, N., Berry, A., Aloe, L., Alleva, E., \& Suomi, S. J. (2009). Early life stress as a risk factor for mental health: Role of neurotrophins from rodents to non-human primates. Neuroscience \& Biobehavioral Reviews, 33, 573-585.

Cohen, R. A., Grieve, S., Hoth, K. F., Paul, R. H., Sweet, L., Tate, D., . . Williams, L. M. (2006). Early life stress and morphometry of the adult anterior cingulate cortex and caudate nuclei. Biological Psychiatry, 59, 975-982.

Coull, J. A. M., Beggs, S., Boudreau, D., Boivin, D., Tsuda, M., Inoue, K., . . . De Koninck, Y. (2005). BDNF from microglia causes the shift in neuronal anion gradient underlying neuropathic pain. Nature, 438, 1017-1021.

Dozier, M., Stoval, K. C., Albus, K. E., \& Bates, B. (2001). Attachment for infants in foster care: The role of caregiver state of mind. Child Development, 72, 1467-1477.

Dube, S. R., Anda, R. F., Whitfield, C. L., Brown, D. W., Felitti, V. J., Dong, M., \& Giles, W. H. (2005). Long-term consequences of childhood sexual abuse by gender of victim. American Journal of Preventive Medicine, 28, $430-438$.

Essex, M. J., Thomas Boyce, W., Hertzman, C., Lam, L. L., Armstrong, J. M., Neumann, S. M. A., \& Kobor, M. S. (2013). Epigenetic vestiges of early developmental adversity: Childhood stress exposure and DNA methylation in adolescence. Child Development, 84, 58-75

Ewald, E. R., Wand, G. S., Seifuddin, F., Yang, X., Tamashiro, K. L., Potash, J. B., ... Lee, R. S. (2014). Alterations in DNA methylation of FKBP5 as a determinant of blood-brain correlation of glucocorticoid exposure. Psychoneuroendocrinology, 44, 112-122.

Fisher, P. A., Gunnar, M. R., Dozier, M., Bruce, J., \& Pears, K. C. (2006). Effects of therapeutic interventions for foster children on behavioral problems, caregiver attachment, and stress regulatory neural systems. Annals of the New York Academy of Sciences, 1094, 215-225.

Francis, D., Diorio, J., Liu, D., \& Meaney, M. J. (1999). Nongenomic transmission across generations of maternal behavior and stress responses in the rat. Science, 286, 1155-1158.

Franklin, T. B., Russig, H., Weiss, I. C., Graff, J., Linder, N., Michalon, A., Vizi, S., \& Mansuy, I. M. (2010). Epigenetic transmission of the impact of early stress across generations. Biological Psychiatry, 68, 408-415.

Fuchikami, M., Morinobu, S., Segawa, M., Okamoto, Y., Yamawaki, S., Ozaki, N., . . . Terao, T. (2011). DNA methylation profiles of the brain-derived neurotrophic factor (BDNF) gene as a potent diagnostic biomarker in major depression. PLOS ONE, 6, e23881.

Gershon, A., Sudheimer, K., Tirouvanziam, R., Williams, L., \& O'Hara, R. (2013). The long-term impact of early adversity on late-life psychiatric disorders. Current Psychiatry Reports, 15, 1-9.

Gorski, J. A., Zeiler, S. R., Tamowski, S., \& Jones, K. R. (2003). Brain-derived neurotrophic factor is required for the maintenance of cortical dendrites. Journal of Neuroscience, 23, 6856-6865.

Guintivano, J., Aryee, M. J., \& Kaminsky, Z. A. (2013). A cell epigenotype specific model for the correction of brain cellular heterogeneity bias and its application to age, brain region and major depression. Epigenetics, 8 , 290-302.

Gunnar, M. R., Frenn, K., Wewerka, S. S., \& Van Ryzin, M. J. (2009). Moderate versus severe early life stress: Associations with stress reactivity and regulation in 10-12-year-old children. Psychoneuroendocrinology, 34, $62-75$.

Hao, Y., Huang, W., Nielsen, D. A., \& Kosten, T. A. (2011). Litter gender composition and sex affect maternal behavior and DNA methylation levels of the oprm1 gene in rat offspring. Frontiers in Psychiatry, 2, 21.

Heim, C., \& Nemeroff, C. B. (2001). The role of childhood trauma in the neurobiology of mood and anxiety disorders: Preclinical and clinical studies. Biological Psychiatry, 49, 1023-1039.

Heim, C., Newport, D. J., Heit, S., Graham, Y. P., Wilcox, M., Bonsall, R., ... Nemeroff, C. B. (2000). Pituitary-adrenal and autonomic responses to stress in women after sexual and physical abuse in childhood. Journal of the American Medical Association, 284, 592-597.
Heim, C., Newport, D. J., Wagner, D., Wilcox, M. M., Miller, A. H., \& Nemeroff, C. B. (2002). The role of early adverse experience and adulthood stress in the prediction of neuroendocrine stress reactivity in women: A multiple regression analysis. Depression and Anxiety, 15, 117-125.

Ikegame, T., Bundo, M., Sunaga, F., Asai, T., Nishimura, F., Yoshikawa, A. ... Iwamoto, K. (2013). DNA methylation analysis of bdnf gene promoters in peripheral blood cells of schizophrenia patients. Neuroscience Research, 77, 208-214.

Ivy, A. S., Brunson, K. L., Sandman, C., \& Baram, T. Z. (2008). Dysfunctional nurturing behavior in rat dams with limited access to nesting material: A clinically relevant model for early-life stress. Neuroscience, 154 , $1132-1142$.

Ivy, A. S., Rex, C. S., Chen, Y., Dubé, C., Maras, P. M., Grigoriadis, D. E., ... Baram, T. Z. (2010). Hippocampal dysfunction and cognitive impairments provoked by chronic early-life stress involve excessive activation of CRH receptors. Journal of Neuroscience, 30, 13005-13015.

Iwamoto, K., Bundo, M., Ueda, J., Oldham, M. C., Ukai, W., Hashimoto, E., ... Kato, T. (2011). Neurons show distinctive DNA methylation profile and higher interindividual variations compared with non-neurons. $G e-$ nome Research, 21, 688-696.

Kawamoto, Y., Nakamura, S., Kawamata, T., Akiguchi, I., \& Kimura, J. (1999). Cellular localization of brain-derived neurotrophic factor-like immunoreactivity in adult monkey brain. Brain Research, 821, 341-349.

Keller, S., Sarchiapone, M., \& Zarrilli, F. (2010). Increased BDNF promoter methylation in the Wernicke area of suicide subjects. Archives of General Psychiatry, 67, 258-267.

Kigar, S. L., Chang, L., Hayne, M. R., Karls, N. T., \& Auger, A. P. (2016). Sex differences in Gadd45b expression and methylation in the developing rodent amygdala. Brain Research, 1642, 461-466.

Kim-Cohen, J., Caspi, A., Taylor, A., Williams, B., Newcombe, R., Craig, I. W., \& Moffitt, T. E. (2006). MAOA, maltreatment, and gene-environment interaction predicting children's mental health: New evidence and a meta-analysis. Molecular Psychiatry, 11, 903-913.

Kolodkin, M. H., \& Auger, A. P. (2011). Sex difference in the expression of DNA methyltransferase $3 \mathrm{a}$ in the rat amygdala during development. Journal of Neuroendocrinology, 23, 577-583.

Kozlenkov, A., Roussos, P., Timashpolsky, A., Barbu, M., Rudchenko, S., Bibikova, M., ... Di Narzo, A. F. (2014). Differences in DNA methylation between human neuronal and glial cells are concentrated in enhancers and non-CpG sites. Nucleic Acids Research, 42, 109-127.

Kundakovic, M., Lim, S., Gudsnuk, K., \& Champagne, F. A. (2013). Sexspecific and strain-dependent effects of early life adversity on behavioral and epigenetic outcomes. Frontiers in Psychiatry, 4, 78.

Lee, J., Duan, W., \& Mattson, M. P. (2002). Evidence that brain-derived neurotrophic factor is required for basal neurogenesis and mediates, in part the enhancement of neurogenesis by dietary restriction in the hippocampus of adult mice. Journal of Neurochemistry, 82, 1367-1375.

Leventopoulos, M., Rüedi-Bettschen, D., Knuesel, I., Feldon, J., Pryce, C. R., \& Opacka-Juffry, J. (2007). Long-term effects of early life deprivation on brain glia in fischer rats. Brain Research, 1142, 119-126.

Li, X., Baker-Andresen, D., Zhao, Q., Marshall, V., \& Bredy, T. W. (2014) Methyl cpg binding domain ultra-sequencing: A novel method for identifying inter-individual and cell-type-specific variation in DNA methylation. Genes, Brain and Behavior, 13, 721-731.

Lister, R., Mukamel, E. A., Nery, J. R., Urich, M., Puddifoot, C. A., Johnson, N. D., . . Ecker, J. R. (2013). Global epigenomic reconfiguration during mammalian brain development. Science, 341, 1237905.

Liu, D., Diorio, J., Tannenbaum, B., Caldji, C., Francis, D., Freedman, A., . . Meaney, M. J. (1997). Maternal care, hippocampal glucocorticoid receptors, and hypothalamic-pituitary-adrenal responses to stress. Science, $277,1659-1662$.

Loman, M. M., \& Gunnar, M. R. (2010). Early experience and the development of stress reactivity and regulation in children. Neuroscience \& Biobehavioral Reviews, 34, 867-876.

Lopez, J. P., Mamdani, F., Labonte, B., Beaulieu, M. M., Yang, J. P., Berlim, M. T., ... Turecki, G. (2013). Epigenetic regulation of BDNF expression according to antidepressant response. Molecular Psychiatry, 18, 398399.

Lowell, A., Renk, K., \& Adgate, A. H. (2014). The role of attachment in the relationship between child maltreatment and later emotional and behavioral functioning. Child Abuse \& Neglect, 38, 1436-1449.

Lubin, F. D., Roth, T. L., \& Sweatt, J. D. (2008). Epigenetic regulation of BDNF gene transcription in the consolidation of fear memory. Journal of Neuroscience, 28, 10576-10586. 
Lupien, S. J., McEwen, B. S., Gunnar, M. R., \& Heim, C. (2009). Effects of stress throughout the lifespan on the brain, behaviour and cognition. $\mathrm{Na}$ ture Reviews Neuroscience, 10, 434-445.

Lutz, P.-E., \& Turecki, G. (2014). DNA methylation and childhood maltreatment: From animal models to human studies. Neuroscience, 264, 142-156.

Lyons-Ruth, K., Pechtel, P., Yoon, S. A., Anderson, C. M., \& Teicher, M. H. (2016). Disorganized attachment in infancy predicts greater amygdala volume in adulthood. Behavioural Brain Research, 308, 83-93.

Marmigère, F., Givalois, L., Rage, F., Arancibia, S., \& Tapia-Arancibia, L. (2003). Rapid induction of BDNF expression in the hippocampus during immobilization stress challenge in adult rats. Hippocampus, 13, 646-655.

Martinowich, K., Hattori, D., Wu, H., Fouse, S., He, F., Hu, Y., . . Sun Y. E. (2003). DNA methylation-related chromatin remodeling in activity-dependent bdnf gene regulation. Science, 302, 890-893.

Martinowich, K., Manji, H., \& Lu, B. (2007). New insights into BDNF function in depression and anxiety. Nature Neuroscience, 10, 1089-1093.

Matevossian, A., \& Akbarian, S. (2008). Neuronal nuclei isolation from human postmortem brain tissue. Journal of Visualized Experiments, 20, e914.

McCarthy, M. M., Auger, A. P., Bale, T. L., De Vries, G. J., Dunn, G. A., Forger, N. G., . . . Wilson, M. E. (2009). The epigenetics of sex differences in the brain. Journal of Neuroscience, 29, 12815-12823.

McEwen, B. S. (2010). Stress, sex, and neural adaptation to a changing environment: Mechanisms of neuronal remodeling. Annals of the New York Academy of Sciences, 1204, 38-59.

McGowan, P. O., Sasaki, A., D’ Alessio, A. C., Dymov, S., Labonte, B., Szyf, M., Turecki, G., \& Meaney, M. J. (2009). Epigenetic regulation of the glucocorticoid receptor in human brain associates with childhood abuse. Nature Neuroscience, 12, 342-348.

Meaney, M. J. (2001). Maternal care, gene expression, and the transmission of individual differences in stress reactivity across generations. Annual Review of Neuroscience, 24, 1161-1192.

Mehta, D., Klengel, T., Conneely, K. N., Smith, A. K., Altmann, A., Pace, T. W., .. . Binder, E. B. (2013). Childhood maltreatment is associated with distinct genomic and epigenetic profiles in posttraumatic stress disorder. Proceedings of the National Academy of Sciences, 110, 8302-8307.

Melas, P. A., Wei, Y., Wong, C. C. Y., Sjöholm, L. K., Åberg, E., Mill, J., Schalling, M., . . Lavebratt, C. (2013). Genetic and epigenetic associations of MAOA and NR3C1 with depression and childhood adversities. International Journal of Neuropsychopharmacology, 16, 1513-1528.

Mirescu, C., Peters, J. D., \& Gould, E. (2004). Early life experience alters response of adult neurogenesis to stress. Nature Neuroscience, 7, 841-846.

Monroy, E., Hernández-Torres, E., \& Flores, G. (2010). Maternal separation disrupts dendritic morphology of neurons in prefrontal cortex, hippocampus, and nucleus accumbens in male rat offspring. Journal of Chemical Neuroanatomy, 40, 93-101.

Monteggia, L. M., Barrot, M., Powell, C. M., Berton, O., Galanis, V., Gemelli, T., . . . Nestler, E. J. (2004). Essential role of brain-derived neurotrophic factor in adult hippocampal function. Proceedings of the National Academy of Sciences, 101, 10827-10832.

Monteggia, L. M., Luikart, B., Barrot, M., Theobold, D., Malkovska, I., Nef, S., ... Nestler, E. J. (2007). Brain-derived neurotrophic factor conditional knockouts show gender differences in depression-related behaviors. Biological Psychiatry, 61, 187-197.

Moore, C. L., \& Morelli, G. A. (1979). Mother rats interact differently with male amd female offspring. Journal of Comparative and Physiological Psychology, 93, 677-684.

Moriceau, S., Shionoya, K., Jakubs, K., \& Sullivan, R. M. (2009). Early-life stress disrupts attachment learning: The role of amygdala corticosterone, locus ceruleus corticotropin releasing hormone, and olfactory bulb norepinephrine. Journal of Neuroscience, 29, 15745-15755.

Mueller, B. R., \& Bale, T. L. (2008). Sex-specific programming of offspring emotionality after stress early in pregnancy. Journal of Neuroscience, 28 , 9055-9065.

Muhammad, A., Carroll, C., \& Kolb, B. (2012). Stress during development alters dendritic morphology in the nucleus accumbens and prefrontal cortex. Neuroscience, 216, 103-109.

Nakajima, K., Honda, S., Tohyama, Y., Imai, Y., Kohsaka, S., \& Kurihara, T. (2001). Neurotrophin secretion from cultured microglia. Journal of Neuroscience Research, 65, 322-331.

Nakajima, K., \& Kohsaka, S. (2001). Microglia: Activation and their significance in the central nervous system. Journal of Biochemistry, 130, 169175.

Naumova, O. Y., Lee, M., Koposov, R., Szyf, M., Dozier, M., \& Grigorenko, E. L. (2012). Differential patterns of whole-genome DNA methylation in institutionalized children and children raised by their biological parents. Development and Psychopathology, 24, 143-155.

Nishioka, M., Shimada, T., Bundo, M., Ukai, W., Hashimoto, E., Saito, T. . Iwamoto K. (2013). Neuronal cell-type specific DNA methylation patterns of the Cacna1c gene. International Journal of Developmental Neuroscience, 31, 89-95.

Nugent, B. M., \& McCarthy, M. M. (2011). Epigenetic underpinnings of developmental sex differences in the brain. Neuroendocrinology, 93, 150-158.

Nugent, B. M., Wright, C. L., Shetty, A. C., Hodes, G. E., Lenz, K. M., Mahurkar, A., . . . McCarthy, M. M. (2015). Brain feminization requires active repression of masculinization via DNA methylation. Nature Neuroscience, 18, 690-697.

Oberlander, T. F., Weinberg, J., Papsdorf, M., Grunau, R., Misri, S., \& Devlin, A. M. (2008). Prenatal exposure to maternal depression, neonatal methylation of human glucocorticoid receptor gene (NR3C1) and infant cortisol stress responses. Epigenetics, 3, 97-106.

Parrish, R. R., Day, J. J., \& Lubin, F. D. (2012). Direct bisulfite sequencing for examination of DNA methylation with gene and nucleotide resolution from brain tissues. Current Protocols in Neuroscience, 60, 1-7.

Pascual, R., \& Zamora-Leon, S. P. (2007). Effects of neonatal maternal deprivation and postweaning environmental complexity on dendritic morphology of prefrontal pyramidal neurons in the rat. Acta Neurobiologiae Experimentalis, 67, 471-479.

Perisic, T., Zimmermann, N., Kirmeier, T., Asmus, M., Tuorto, F., Uhr, M., . . Zschocke, J. (2010). Valproate and amitriptyline exert common and divergent influences on global and gene promoter-specific chromatin modifications in rat primary astrocytes. Neuropsychopharmacology, 35 , 792-805.

Perroud, N., Paoloni-Giacobino, A., Prada, P., Olie, E., Salzmann, A., Nicastro, R., ... Malafosse, A. (2011). Increased methylation of glucocorticoid receptor gene (NR3C1) in adults with a history of childhood maltreatment: A link with the severity and type of trauma. Translational Psychiatry, 1, e 59 .

Perroud, N., Salzmann, A., Prada, P., Nicastro, R., Hoeppli, M. E., Furrer, S., ... Malafosse, A. (2013). Response to psychotherapy in borderline personality disorder and methylation status of the bdnf gene. Translational Psychiatry, 3, e207.

Pickreign Stronach, E., Toth, S. L., Rogosch, F., Oshri, A., Manly, J. T., \& Cicchetti, D. (2011). Child maltreatment, attachment security, and internal representations of mother and mother-child relationships. Child Maltreatment, 16, 137-145.

Prados, J., Stenz, L., Courtet, P., Prada, P., Nicastro, R., Adouan, W., . . Perroud, N. (2015). Borderline personality disorder and childhood maltreatment: A genome-wide methylation analysis. Genes, Brain and Behavior, $14,177-188$

Rasmusson, A. M., Shi, L., \& Duman, R. (2002). Downregulation of BDNF mRNA in the hippocampal dentate gyrus after re-exposure to cues previously associated with footshock. Neuropsychopharmacology, 27, 133-142.

Riggs, S. A., Cusimano, A. M., \& Benson, K. M. (2011). Childhood emotional abuse and attachment processes in the dyadic adjustment of dating couples. Journal of Counseling Psychology, 58, 126-138.

Riley, C., Cope, T., \& Buck, C. (2004). CNS neurotrophins are biologically active and expressed by multiple cell types. Journal of Molecular Histology, 35, 771-783.

Roisman, G. I., \& Fraley, R. C. (2008). A behavior-genetic study of parenting quality, infant attachment security, and their covariation in a nationally representative sample. Developmental Psychology, 44, 831-839.

Roth, T. L., Lubin, F. D., Funk, A. J., \& Sweatt, J. D. (2009). Lasting epigenetic influence of early-life adversity on the BDNF gene. Biological Psychiatry, 65, 760-769.

Roth, T. L., Matt, S., Chen, K., \& Blaze, J. (2014). Bdnf DNA methylation modifications in the hippocampus and amygdala of male and female rats exposed to different caregiving environments outside the homecage. $D e-$ velopmental Psychobiology, 56, 1755-1763.

Roth, T. L., \& Sullivan, R. M. (2005). Memory of early maltreatment: Neonatal behavioral and neural correlates of maternal maltreatment within the context of classical conditioning. Biological Psychiatry, 57, 823-831.

Roth, T. L., Zoladz, P. R., Sweatt, J. D., \& Diamond, D. M. (2011). Epigenetic modification of hippocampal Bdnf DNA in adult rats in an animal model of post-traumatic stress disorder. Journal of Psychiatric Research, 45, 919-926.

Schwarz, J. M., Hutchinson, M. R., \& Bilbo, S. D. (2011). Early-life experience decreases drug-induced reinstatement of morphine CPP in adult- 
hood via microglial-specific epigenetic programming of anti-inflammatory IL-10 expression. Journal of Neuroscience, 31, 17835-17847.

Shah, P., Fonagy, P., \& Strathearn, L. (2010). Is attachment transmitted across generations? The plot thickens. Clinical Child Psychology and Psychiatry, 15, 329-345.

Smith, A. K., Kilaru, V., Klengel, T., Mercer, K. B., Bradley, B., Conneely, K. N., . . Binder, E. B. (2015). DNA extracted from saliva for methylation studies of psychiatric traits: Evidence tissue specificity and relatedness to brain. American Journal of Medical Genetics, 168, 36-44.

Song, Y., Miyaki, K., Suzuki, T., Sasaki, Y., Tsutsumi, A., Kawakami, N., ... Kan, C. (2014). Altered DNA methylation status of human brain derived neurotrophic factor gene could be useful as biomarker of depression. American Journal of Medical Genetics Part B: Neuropsychiatric Genetics, 165, 357-364.

Spiers, H., Hannon, E., Schalkwyk, L. C., Smith, R., Wong, C. C. Y., O’Donovan, M. C., . . . Mill, J. (2015). Methylomic trajectories across human fetal brain development. Genome Research, 25, 338-352.

St.-Cyr, S., \& McGowan, P. (2015). Programming of stress-related behavior and epigenetic neural gene regulation in mice offspring through maternal exposure to predator odor. Frontiers in Behavioral Neuroscience, 9, 145.

Stenz, L., Zewdie, S., Laforge-Escarra, T., Prados, J., La Harpe, R., Dayer, A., . . . Aubry, J.-M. (2015). BDNF promoter I methylation correlates between post-mortem human peripheral and brain tissues. Neuroscience Research, 91, 1-7.

Styron, T., \& Janoff-Bulman, R. (1997). Childhood attachment and abuse: Long-term effects on adult attachment, depression, and conflict resolution. Child Abuse \& Neglect, 21, 1015-1023.

Sun, W., Zang, L., Shu, Q., \& Li, X. (2014). From development to diseases: The role of 5-hmc in brain. Genomics, 104, 347-351.

Teicher, M. H., Andersen, S. L., Polcari, A., Anderson, C. M., Navalta, C. P., $\&$ Kim, D. M. (2003). The neurobiological consequences of early stress and childhood maltreatment. Neuroscience \& Biobehavioral Reviews, 27, 33-44.

Teicher, M. H., \& Samson, J. A. (2016). Annual research review: Enduring neurobiological effects of childhood abuse and neglect. Journal of Child Psychology and Psychiatry, 57, 241-266.

Thompson, M., Kingree, J., \& Desai, S. (2004). Gender differences in longterm health consequences of physical abuse of children: Data from a nationally representative survey. American Journal of Public Health, 94, 599-604.

Trainor, B. C., Pride, M., Landeros, R. V., Knoblauch, N. W., Takahashi, E. Y., Silva, A. L., \& Crean, K. C. (2011). Sex differences in social interaction behavior following social defeat stress in the monogamous california mouse (Peromyscus californicus). PLOS ONE, 6, e17405.

Tyrka, A. R., Price, L. H., Marsit, C., Walters, O. C., \& Carpenter, L. L. (2012). Childhood adversity and epigenetic modulation of the leukocyte glucocorticoid receptor: Preliminary findings in healthy adults. PLOS ONE, 7, e30148.

Uchida, S., Hara, K., Kobayashi, A., Funato, H., Hobara, T., Otsuki, K., . . . Watanabe, Y. (2010). Early life stress enhances behavioral vulnerability to stress through the activation of REST4-mediated gene transcription in the medial prefrontal cortex of rodents. Journal of Neuroscience, 30 , 15007-15018.

Unternaehrer, E., Meyer, A. H., Burkhardt, S. C., Dempster, E., Staehli, S., Theill, N., . . M Meinlschmidt, G. (2015). Childhood maternal care is associated with DNA methylation of the genes for brain-derived neurotrophic factor (BDNF) and oxytocin receptor (OXTR) in peripheral blood cells in adult men and women. Stress, 18, 451-461.

Vythilingam, M., Heim, C., Newport, J., Miller, A. H., Anderson, E. Bronen, R., . . . Charney, D. S. (2002). Childhood trauma associated with smaller hippocampal volume in women with major depression. American Journal of Psychiatry, 159, 2072-2080.

Walton, E., Hass, J., Liu, J., Roffman, J. L., Bernardoni, F., Roessner, V., . . Ehrlich, S. (2016). Correspondence of DNA methylation between blood and brain tissue and its application to schizophrenia research. Schizophrenia Bulletin, 42, 406-414.

Wang, A., Nie, W., Li, H., Hou, Y., Yu, Z., Fan, Q., \& Sun, R. (2014). Epigenetic upregulation of corticotrophin-releasing hormone mediates postnatal maternal separation-induced memory deficiency. PLOS ONE, 9, e94394.

Weaver, I. C., Cervoni, N., Champagne, F. A., D’Alessio, A. C., Sharma, S., Seckl, J. R., . . Meaney, M. J. (2004). Epigenetic programming by maternal behavior. Nature Neuroscience, 7, 847-854

Wei, R., Lin, C.-M., \& Tu, Y.-Y. (2010). Strain-specific BDNF expression of rat primary astrocytes. Journal of Neuroimmunology, 220, 90-98.

Weiss, I. C., Franklin, T. B., Vizi, S., \& Mansuy, I. M. (2011). Inheritable effect of unpredictable maternal separation on behavioral responses in mice. Frontiers in Behavioral Neuroscience, 5, 3.

Willing, J., Kim, T., Brodsky, L., Cortes, L., \& Juraska, J. M. (2014) Puberty-induced changes in neuron and glia number in the prefrontal cortex of male and female rats. Paper presented at the International Society for Developmental Psychobiology Annual Meeting, Washington, DC.

Wu, X., Chen, P. S., Dallas, S., Wilson, B., Block, M. L., Wang, C. C., . . Hong, J.-S. (2008). Histone deacetylase inhibitors up-regulate astrocyte GDNF and BDNF gene transcription and protect dopaminergic neurons. International Journal of Neuropsychopharmacology, 11, 1123-1134.

Zhang, J., Qin, L., \& Zhao, H. (2013). Early repeated maternal separation induces alterations of hippocampus reelin expression in rats. Journal of Biosciences, 38, 27-33. 